\title{
Research on the Role of Accounting Informationization Management in Enterprise Management
}

\author{
Guo Wenjun \\ Xi'an Aeronautical Polytechnic institute, Shaanxi, China, 710089
}

Keywords: enterprise management; accounting informationization; role and function

\begin{abstract}
Under the tide of information age, management of accounting informationization has become an important symbol of the competitiveness of enterprises. The promotion of accounting informationization management is not only related to the efficiency of internal control mechanism of enterprises, but also an important way for enterprises to promote their own transformation and upgrading. In the application process of accounting informationization management, it brings many benefits to the internal control system of enterprise, which not only improves the efficiency of accounting treatment, but also promotes the pace of enterprise information development, but at the same time there are some problems. This paper studies the application status of accounting informationization management, and probes into some problems in the application of accounting informatization, and puts forward some corresponding countermeasures.
\end{abstract}

\section{Introduction}

Nowadays, more and more companies have realized the importance of information technology in enterprise management. The construction of enterprise information has become a necessary prerequisite for the development of modern enterprises and enhancing their overall competitiveness [1]. Enterprise management and informatization have also caused extensive discussion and attention among companies as two hot topics. To use capital efficiently and maximize the value of the company, effective and timely information support is essential.

However, some companies still have insufficient understanding of financial informationization. Simply understanding information as accounting processing with computers only liberates financial personnel from manual accounting, and does not reflect the role of financial informationization. There are also some companies in the corporate group do not have a link between the molecular information system, which greatly reduces the overall corporate information processing efficiency, so that companies cannot effectively manage, but also take time to focus on the information of the various companies. Therefore, it is particularly important to apply information technology to management and use the perspective of management accounting to improve the current financial informationization process.

\section{Characteristics \& Contents of Accounting Informationization}

\subsection{Characteristics of accounting informationization}

The realization of the accounting informationization, mainly relying on advanced information technology and modern management concepts. It is under the application of comprehensiveness, to realize the informatization goal of financial management. In this process, advanced information technology is the foundation for realizing financial management informationization, and financial information resources are taken as important strategic resources for the company [2]. Through the goal of accounting informationization, the potential of financial human resources information can be mobilized. First of all, from the perspective of the characteristics of enterprise financial management accounting informationization, it is reflected in multiple levels. Financial management accounting informationization is undoubtedly the application of modern management techniques, and can effectively achieve networked financial management. The application of this technology can 
effectively achieve the goal of remote processing of financial information, and can improve the overall efficiency of financial information management.

Accounting informationization is dynamic and integrated. From the perspective of dynamic analysis, the dynamic characteristics of accounting informationization are mainly reflected in the dynamics of accounting information collection and the effectiveness of accounting information processing. Accounting information is an important basis for the company's financial processing. The comprehensiveness and accuracy of accounting information directly affect the financial information of the company. The integrity of the financial processing will have a certain impact [3]. Based on the development and application of accounting information, when the accounting information system is used to deal with the acquired accounting information, whether the entry of accounting information in the system is timely or not is related to the success of the financial accounting of the enterprise, which determines whether the financial status of the enterprise can be actually fed back. From the analysis of integration, the integrated features of accounting informationization are mainly reflected in three aspects: the integration of accounting information, the integration of internal and external information systems, and the integration of enterprise finance and business. Based on the comprehensive characteristics of accounting informationization, through the correct understanding of accounting informationization, innovation of accounting techniques will help improve the financial management level of the company and promote the healthy and sustainable development of the company.

\subsection{Contents of accounting informationization}

The content of accounting informatization involves a wide range, in which accounting information processing system is an important information part. This content is a system that manages the economic business of an enterprise. It has a variety of functions in this management system. Each function is responsible for specific management tasks, so that it can communicate information and improve the overall system goals. Furthermore, the content of the decision support system for financial information management is a more flexible interactive system that can accurately determine semi-structured and unstructured financial issues. Through the application of this system content, the actual financial situation can be analyzed. This lays the foundation for the accuracy of business decisions.

\section{The Influence of Accounting Informationization on Enterprise Management}

\subsection{Favorable influence}

Accounting informationization is the innovation of accounting information processing technologies and models, which helps to improve the quality and efficiency of accounting information processing. Through the promotion of accounting informationization in corporate management, it can not only achieve the network computing of financial information of enterprises, but also expand the scope and space of financial management of enterprises, which is of great significance in improving the financial management level of enterprises. Accounting informationization involves the application of various advanced science and technology such as computer technology and network technology, improving the accounting information processing technologies and models. Based on the development of accounting information, accounting personnel can use computer systems to perform high quality and efficient processing of corporate financial data in enterprises management, and use financial data to truly reflect the financial status of the enterprise, comprehensively monitor the company's cash flow, and promote the healthy development of corporate finances. It can realize the networked processing of financial information of the enterprise, which is beneficial to the improvement of the quality and efficiency of the enterprise management.

Under the background of accounting informationization, the scope and space of corporate management have been further expanded, and accounting information processing methods have also been innovative. The accounting personnel of the enterprise can use professional accounting information systems to process financial data, optimize the allocation of corporate financial resources, provide scientific basis for the operation and decision-making of enterprises, increase the utilization 
rate of funds of enterprises, and promote the improvement of the enterprises management level. The informatization development of enterprise financial management can help solve the problem of financial communication among various departments of the company in a timely manner and improve the timeliness of business procedures. In the enterprise financial management, through the application of professional financial management software, using the corresponding information network to accurately record the company's real-time financial status, strengthen the economic business exchanges between various departments of the company, and have a certain degree of coordination of the financial treatment of various departments of the company. The role will be conducive to improving the quality and efficiency of corporate financial management, so as to promote the healthy and sustainable development of the company.

\subsection{Adverse effects}

Under the background of accounting informatization, corporate financial management often encounters problems such as repeated errors in financial data, excessive data concentration, and imprecise system design, which also reflects the adverse effects of accounting informationization on corporate financial management. Accounting informationization mainly uses advanced accounting information systems to process accounting information and corporate financial data. The standardization of computer operations, the suitability and scientificness of the preparation of system programs directly affect the quality and efficiency of corporate financial management. Among them, the preparation of accounting information system-related procedures is based on financial data such as corporate financial statements, so if corporate financial information repeated data errors, it will cause system programming problems, affect the use of accounting information systems, which is not conducive to processing corporate financial data.

\section{Countermeasures for Enterprise Management under the Background of Accounting Informationization}

\subsection{Optimize the enterprise financial management system}

The development of accounting informationization puts forward higher requirements on the financial management of enterprises, which is related to the development of enterprises [4]. Under the background of accounting information, the improvement of the enterprise financial management, should be based on the development of accounting information and the present situation of financial management, and combine the innovation of accounting technology and model, formulating the target of financial management in accordance with the law of the development of the market economy and accounting information, optimizing the enterprise financial management system, combining the use of the human mechanism and the training mechanism of talent, and optimizing the enterprise financial management system. Establishing a perfect and suitable financial management system for enterprises, strengthen the professional skills and comprehensive quality training of the financial personnel, strengthen the understanding of the financial personnel to the accounting information, standardize the operation behavior of the accounting information system, and improve the information level of the financial personnel.

Regarding the training of financial management personnel, it is necessary to adopt a scientific and appropriate method to conduct comprehensive training, clarify the training objectives, and fully take the actual situation into consideration. Perfect and appropriate financial management system to improve the actual operation ability of financial management personnel, prompting correct understand of the accounting informationization's impact on enterprise financial management and improve the level of financial management so as to provide guarantees for the healthy operation and sustainable development of the enterprise.

\subsection{Optimize the enterprise financial software}

The professional financial software is an important basis for the promotion of enterprise financial management informationization. The suitability and scientificity of the financial software are related 
to the information processing level of the enterprise financial data, which directly affects the quality and efficiency of the enterprise financial management. Based on the development of accounting informationization, to enhance enterprises financial management level, enterprises should optimize financial software according to the actual situation of financial management and the needs of informatization, select more comprehensive financial software. And use the ERP software to fully budget the production and operation of the enterprise and the supervision of the enterprise. Enhance corporate financial management, and ensure the orderly conduct of financial management and financial data processing, provide scientific basis for the operation and decision of the enterprise.

\section{Summary}

Financial management as an important part of enterprise management has important influence on the enterprise competitiveness and management. Based on the development of accounting informationization, the scope of enterprise management has been further expanded, but the existing security risks have become increasingly prominent. Therefore, to ensure the management level of the enterprise in the context of accounting informationization, it is necessary to establish a sound enterprise financial management based on the current status of the demand for informatization development, combined with the innovation of accounting technology, ideas and models. Improving the quality of financial management personnel, and the quality and efficiency of financial management, promote the healthy and sustainable development of the enterprise.

\section{Acknowledgement}

The backbone Specialty Construction Project of the Action Plan for Innovation and Development of higher Vocational Education-aerial crew Specialty Project No.: XM-1-2

\section{References}

[1] Han Xiangdong. Successful mirror of management accounting informatization[J]. Friend of Accounting, 2014, (32), p.88.

[2] Lu Yunxia, The development of management accounting informatization in China[J]. China's market, 2015, (26), p.101

[3] Jiang Wu Yifan, Research on the status and path of informatization construction of China's management accounting [J]. Business Review, 2016, p.72

[4] Di Yu Jiang. Problems and Countermeasures of the development of management accounting informatization in China[J]. Finance and Economics, 2016, (5), p.219 